\title{
Eksplorasi material daur ulang kantong plastik dengan teknik origami
}

\author{
Devanny Gumulya *
}

Program Studi Desain Produk, Universitas Pelita Harapan, Tangerang, Indonesia

\begin{abstract}
Shopping plastik bag is a thermoplastik type LDPE and HDPE, that can be heated with hotpress. Through this recycling process come new material that can used for product material. The recycle plastik material has a lot of potential to be used as a product application. market research From founded many brands that try to recycle plastik still using another new material to give support to the plastik recycle material. Origami is a paper folding art that is commonly known by everyone. The study tried to apply the origami technique on recycled plastik bag material that has been heated with hotpress machine. With origami technique $90 \%$ the product can be made with this material entirely without the help of sewing and other materials. This is seen as an opportunity for the market that still use many new materials to support this material. The folding gives construction to the one sheet material and give new function to the recycle plastik material. The research uses experimental method. Series of paper origami patterns are applied on the recycle material, till founded several folding that can be apply on the recycle plastik sheet material. The research result is a variety of functional products made with origami techniques that have been egistered design industry copy wright.
\end{abstract}

Key words: LDEP plastik waste, recycling, product design

\begin{abstract}
Abstrak
Kantong plastik belanja yang berjenis termoplastik tipe LDPE dan HDPE, dipanaskan dengan hotpress dapat dijadikan lembaran yang dapat siap diolah sebagai bahan produk, Material daur ulang ini memiliki banyak potensi untuk dijadikan aplikasi produk. Berdasarkan riset pasar, banyak brand yang mendaur ulang sampah plastik, tapi masih banyak menggunakan material lain untuk mendukung material ini. Origami adalah seni melipat kertas yang dikenal semua orang. Penelitian ini mencoba mengaplikasikan teknik origami pada material daur ulang kantong plastik yang sudah dipanaskan dengan mesin hotpress. Dengan teknik origami $90 \%$ produk dapat dibuat penuh dengan material ini tanpa bantuan jahit dan material lainnya, dari selembar material daur ulang dengan konstruksi lipatan material menjadi kuat untuk dibuat produk. Teknik ini bisa menjadi alternative di pasar yang masih banyak menggunakan material baru untuk mendaur ulang plastik. Metode penelitian ada eksperimen uji coba aneka pola origami kertas pada material plastik hingga didapatkan dasar - dasar lipatan yang dapat diaplikasikan pada material daur ulang. Hasilnya adalah aneka produk fungsional dibuat dengan teknik origami yang sudah didaftarkan HAKI desain industri.
\end{abstract}

Kata kunci: plastik LDPE, daur ulang, desain produk

\section{Pendahuluan}

Pencemaran lingkungan oleh sampah plastik mendorong munculnya banyak start up desain produk yang mencoba mengolah sampah plastik dengan menggunakan pendekatan upcycling, sebuah proses dimana material diubah menjadi sesuatu yang lebih bernilai dan berkualitas dari sebelumnya. Pendekatan ini banyak digunakan, karena menjanjikan mengurangi penggunaan material dan energi (Sung, 2015). Upaya pengolahan limbah kantong plastik sudah dilakukan dengan tujuan untuk dimanfaatkan sebagai material produk fungsional (Gumulya, dkk, 2020).

Beberapa brand juga sudah secara khusus membuat produk dari material yang diperoleh melalui proses

\footnotetext{
* Corresponding author Tel : +62-888-8564-165 ; e-mail : devanny.gumulya@uph.edu
} 
mendaur ulang sampah kantong plastik antara lain adalah Kreskros, Reform, Nur Fashion Art, Misenio.

Kreskros. Sebuah brand produk yang berdiri sejak tahun 2016. Kegiatannya adalah mengolah sampah kantong plastik dengan merajut plastik dikombinasikan dengan benang. Pertama - tama plastik digunting hingga seperti benang, dan perlahan - lahan plastik dirajut dengan benang. Produk yang dihasikan adalah aneka model tas. Brand ini mengolah sampah plastik dari sebuah pabrik di Ambarawa, Jawa Tengah dan mengembangkan komunitas ibu - ibu setempat untuk merajut plastik. Keunikan bahan kreskros adalah plastik yang dikombinasikan dengan benang, karena bila 100\% plastik yang dirajut material akan menjadi kasar (Gambar 1).

Reform.Sebuah brand asal Mesir yang sudah memenangkan banyak penghargaan internasional di bidang desain, karena mendaur ulang sampah kantong plastik dengan menenun plastik di mesin alat tenun bukan mesin (ATBM). Plastik juga dikombinasikan dengan benang. Pengrajin ATBM di Egypt sudah semakin sedikit dan tidak ada generasi penerus. Reform mencoba memulihkan industri ini, dengan membawa material baru. Hasilnya plastik bisa menjadi bahan untuk homedecor seperti upholstery untuk furnitur (Gambar 2).

Nur Fashion Art. UMKM (Usaha Mikro, Kecil, dan Menengah) asal Tegal yang mendaur ulang sampah kantong plastik dengan menyetrika kantong plastik (plastik fusing), baru menjahitnya menjadi aneka tas, sepatu, dan dompet (Gambar 3).

Misenio. Sebuah brand sejak tahun 2017 yang mendaur ulang sampah kantong plastik dengan menyetrika kantong plastik (plastik fusing), menjahitnya menjadi aneka alat bawa mulai dari tas hingga kantong - kantong untuk kebutuhan travel (Gambar 4).

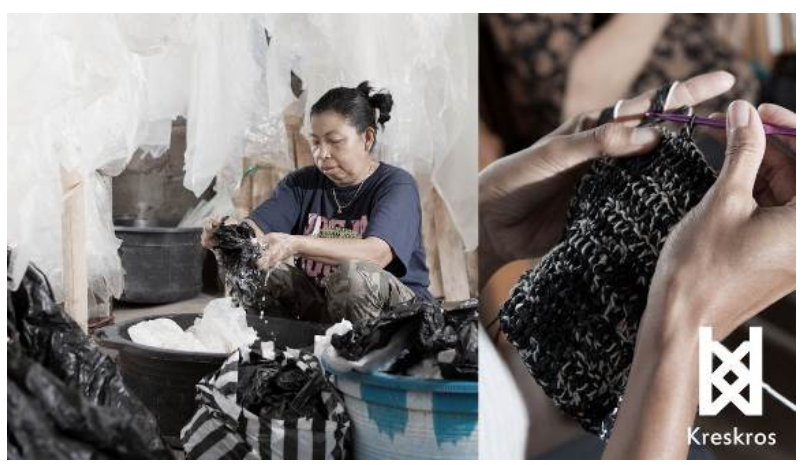

Gambar 1. Kreskros (Sumber: http://kreskros.com)

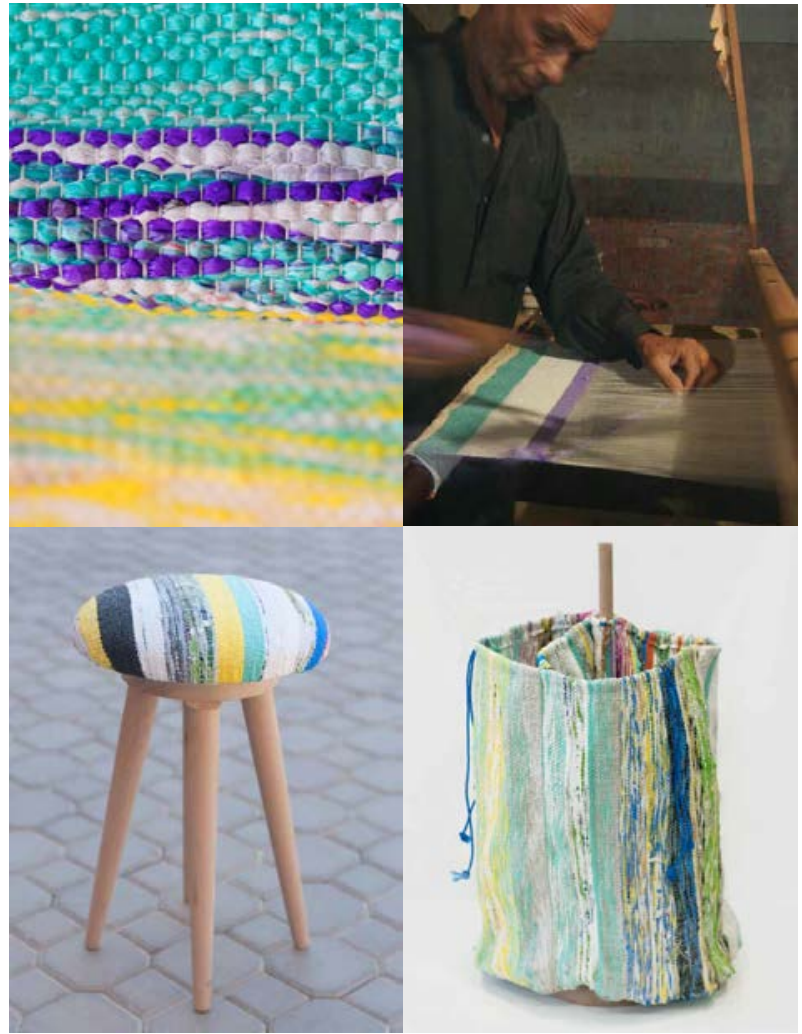

Gambar 2. Produk Reform (Sumber: https://reformstudio.net/)

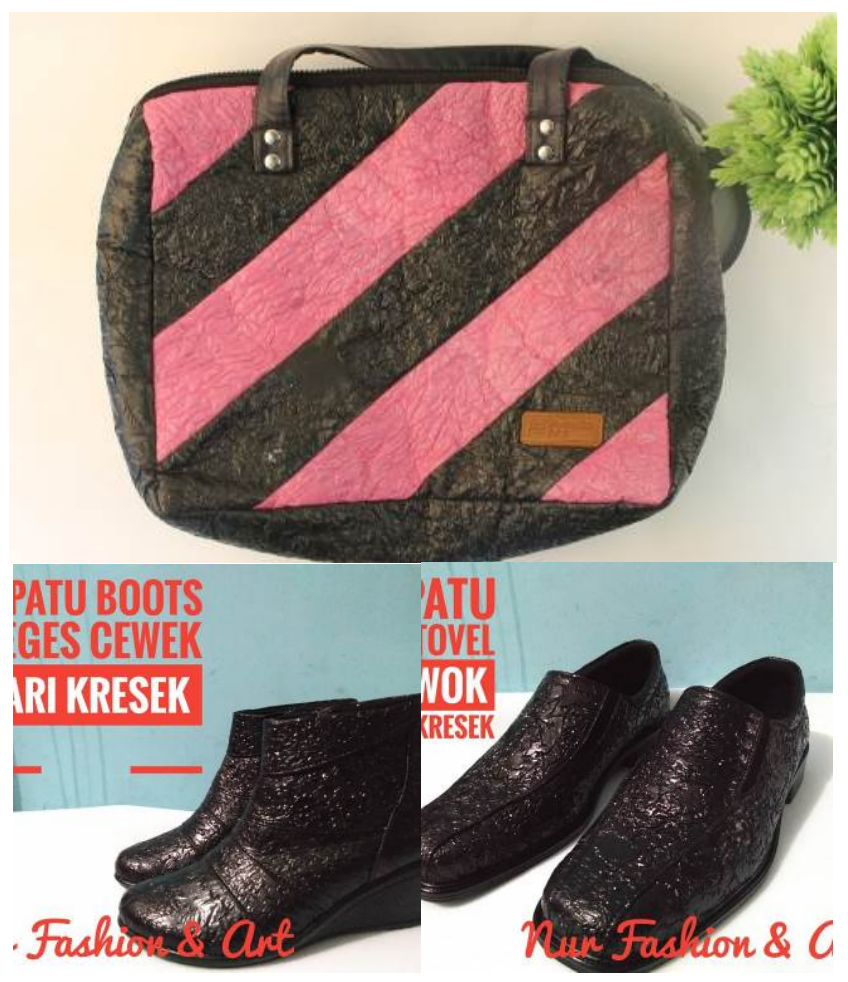

Gambar 3. Produk Nur Fashion Art (Sumber: Nur Fashion Art Instagram) 
Devanny Gumulya

Eksplorasi material daur ulang kantong plastik dengan teknik origami
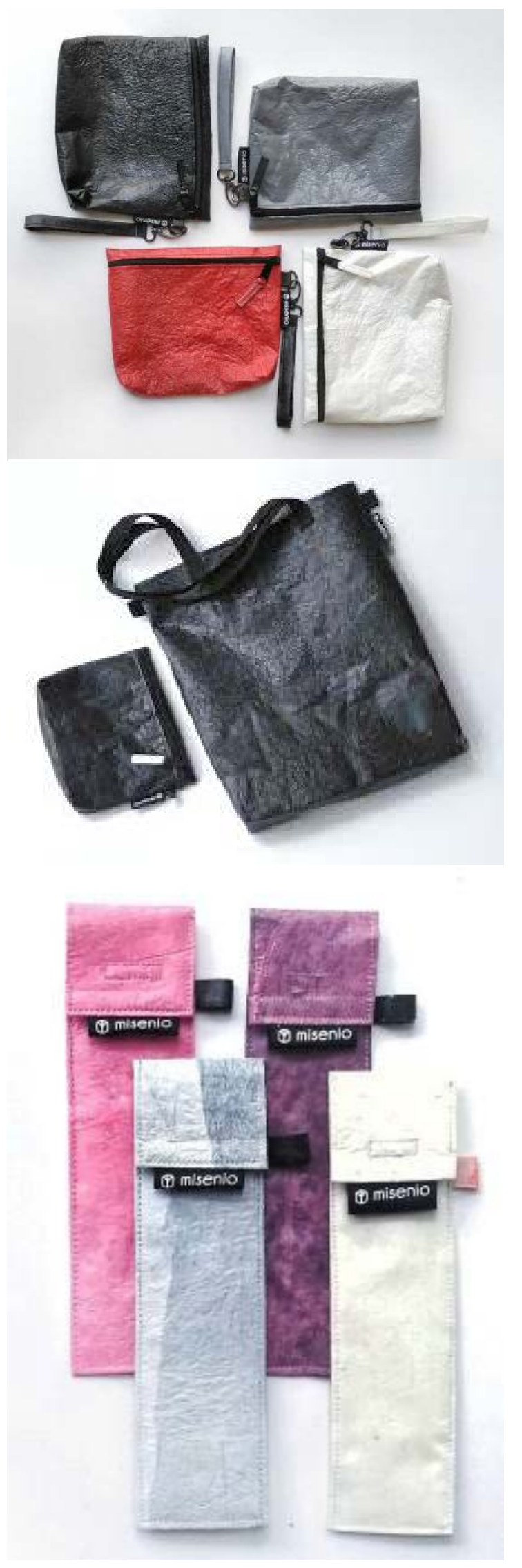

Gambar 4. Produk Misenio (Sumber: www.misenio.com)

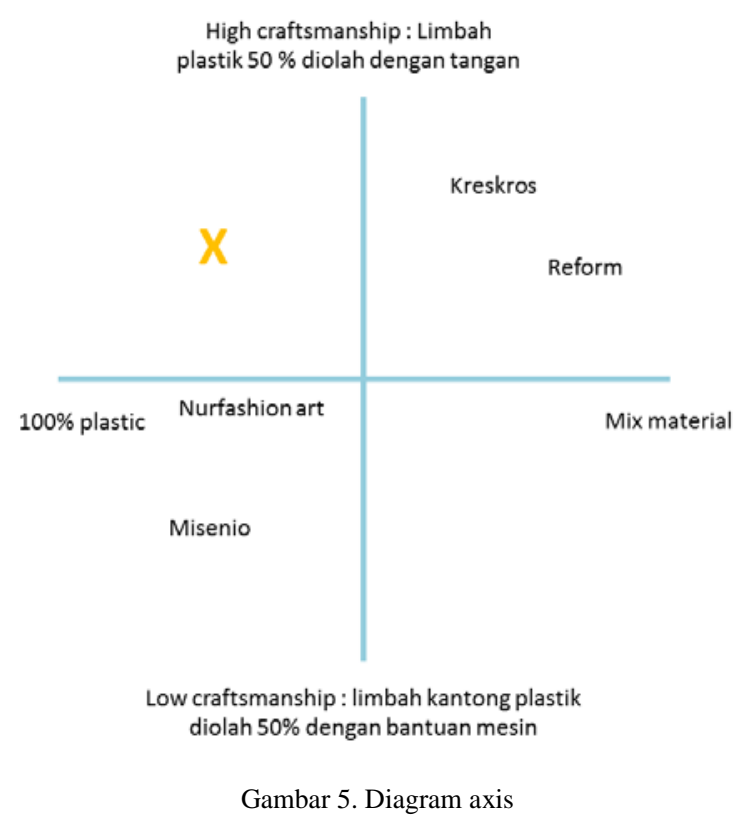

Beberapa brand tersebut selanjutnya dianalisa lebih lanjut dengan diagram axis (Gambar 5). Studi kasus dibagi berdasarkan tingkat craftsmanship yang digunakan dan material yang digunakan. Kreskros dan reform ada di area high craftsmanship dan mix material karena keduanya mendaur ulang plastik mulai dari membersihkan, memotong halus - halus plastik menjadi seperti benang baru plastik mulai dirajut atau ditenun, langkah - langkah ini semua membutuhkan keahlian tangan yang tinggi. Plastik dikombinasikan dengan benang, agar material lebih halus dan tidak putus karena plastik kalau ditarik akan putus. Nur Fashion Art dan Misenio ada di area low craftsmanship dan $100 \%$ plastik, karena plastik didaur ulang dengan dipanaskan lalu dijahit, jadi sebagian besar prosesnya dibantu dengan mesin sehingga prosesnya jauh lebih singkat dari kreskros dan reform. Arah penelitian ini ada di area high craftsmanship dan $100 \%$ plastik, karena aplikasi teknik origami pada plastik membutuhkan keahlian craftsmanship yang baik, dan harus presisi. Seperti yang sudah disebutkan sebelumnya teknik origami bisa membuat material menjadi kuat. Jadi produk bisa dibuat $70-100 \%$ dari plastik.

\section{Kebaruan Penelitian}

Melihat banyaknya muncul brand produk yang mengolah sampah kantong plastik dapat dikatakan bahwa saat ini pasar sudah sangat mengerti bahwa sampah plastik harus diolah. Setiap brand memiliki keunikannya sendiri dalam proses daur ulang mereka ada yang dirajut, ditenun dan plastik dikombinasikan dengan material lain seperti benang, kulit untuk 
meningkatkan value-nya. Seperti yang dijelaskan pada diagram axis di atas, penelitian ini berada di area yang belum pernah diteliti orang sebelumnya. Saat ini belum pernah ada yang mencoba menerapkan teknik origami pada material daur ulang plastik. Teknik origami sudah banyak dikembangkan di bermacam - macam material, kali ini dicoba pada material plastik. Tujuan penelitian ini adalah (1) Menguji coba aplikasi teknik origami pada material daur ulang yang belum pernah dicoba sebelumnya dan (2) Memberikan tutorial teknik melipat plastik.

\section{Bahan dan metode}

Kata origami adalah kata gabungan dari dua kata dari bahasa Jepang, yaitu ori yang berarti melipat dan gami yang berarti kertas. Jadi origami berarti seni melipat kertas. Sejarah tidak mencatat siapa penemu origami, tapi semua berawal dari penemuan kertas di Cina di abad 1, dan dibawa ke Jepang pada abad ke 6 oleh seorang biksu. Jadi belum bisa ditelusuri origami bermula di Cina atau Jepang. Instruksi origami umumnya diturunkan secara turun temurun (origamiinstructions.com, 2015)

Pada awalnya origami dipandang sebagai seni untuk golongan elit, karena kertas mahal dan sulit didapatkan masyarakat umum. Biksu Jepang melipat untuk tujuan spiritual dan sering digunakan untuk upacara keagamaan. Kemajuan teknologi membuat produksi kertas makin cepat dan murah, akhirnya kertas menjadi mudah didapat dan origami dapat menjadi hobi semua orang. Sampai saat ini origami diterapkan sebagai bagian dari pelajaran di sekolah pendidikan anak usia dini (PAUD) di seluruh dunia, termasuk Indonesia.

Menurut ensiklopedia seni Asia, teknik origami dibagi menjadi 5 jenis, yaitu: Action origami, Modular origami, Wet Folding, Origami Tesselations, dan Origami Architecture. Action origami merupakan model origami yang terlihat unik bila digerakkan. Model yang paling mudah dibuat dengan teknik ini adalah pesawat terbang seperti tampak pada Gambar 6. Teknik kedua adalah modular origami, yaitu model origami yang terdiri dari beberapa modul yang baru terbentuk bila digabungkan menjadi satu (Gambar 7). Teknik origami berikutnya adalah Wet Folding. Teknik origami ini dikembangkan oleh Akira Yoshikawa. Sebelum dilipat kertas disemprot dengan air sedikit jadi lebih lunak, lalu ditekuk secara perlahan-lahan dengan garis tidak tegas. Teknik ini cocok untuk bentuk - bentuk organik, seperti bentuk muka binatang (Gambar 8).

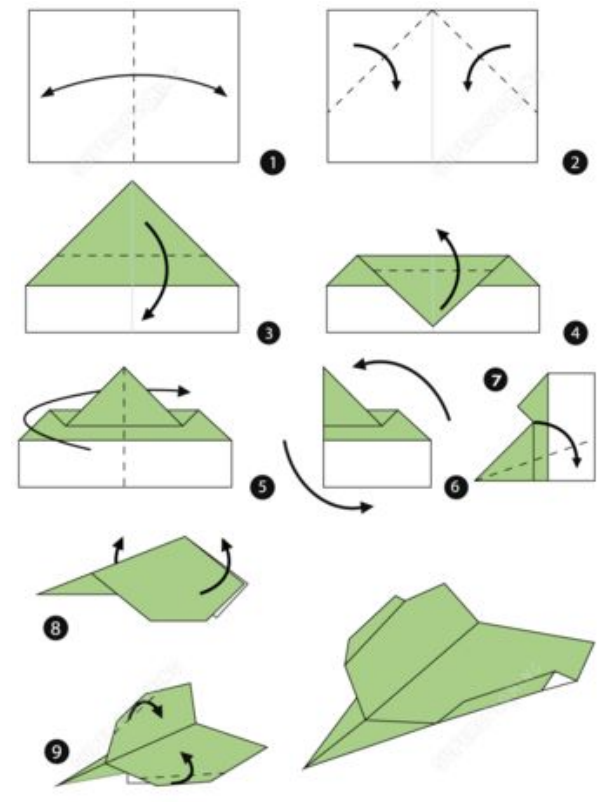

Gambar 6. Contoh Action Origami

(Sumber: http://www.visual-arts-cork.com/east-asian-art/origami.htm)

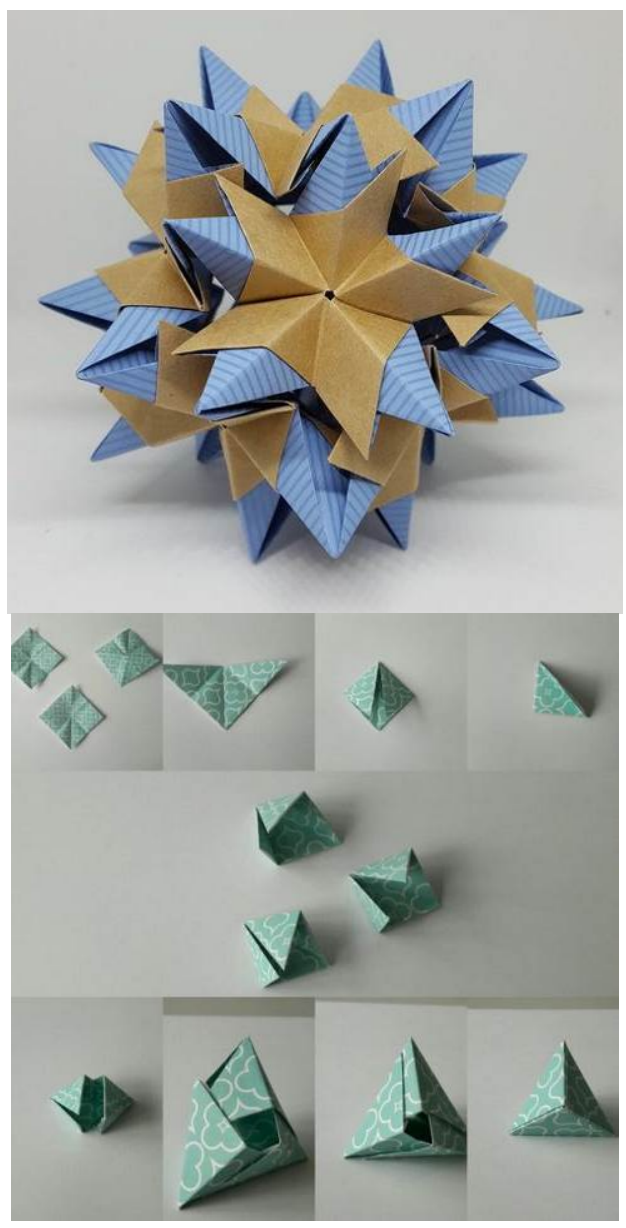

Gambar 7. Contoh Modular Origami

(Sumber: http://www.visual-arts-cork.com/east-asian-art/origami.htm) 


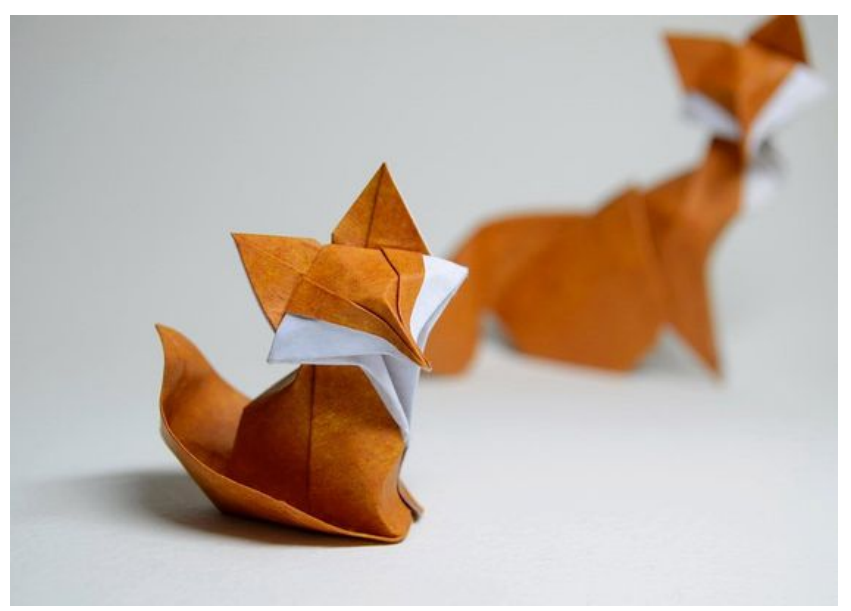

Gambar 8. Contoh Wet Folding atau Wet Origami (Sumber: http://www.visual-arts-cork.com/east-asian-art/origami.htm)

(a)
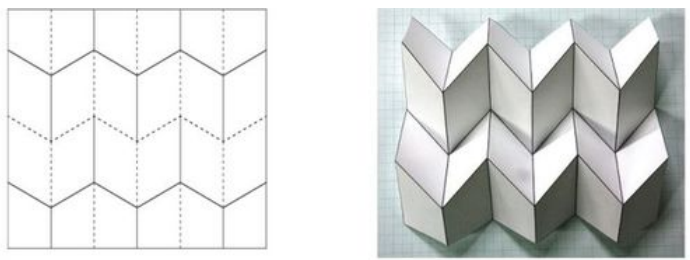

(b)

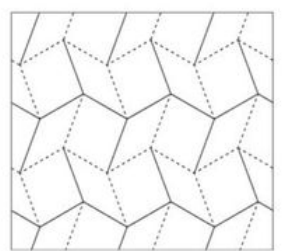

(c)
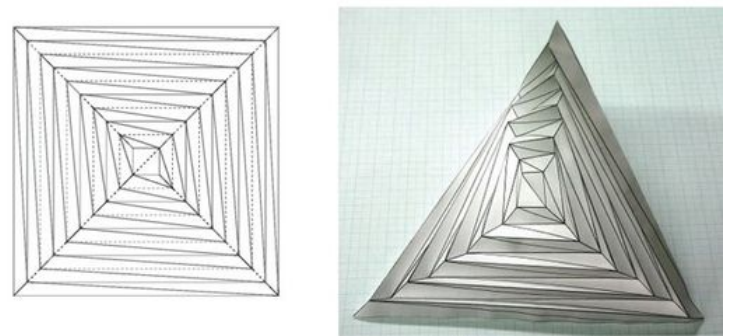

Gambar 9. Contoh Origami Tesselations

(Sumber: http://www.visual-arts-cork.com/east-asian-art/origami.htm)

Selanjutnya teknik Origami Tesselations, yaitu teknik melipat dengan pola bentuk - bentuk yang disusun berdekatan ataupun bertumpuk. Pada umumnya mengambil bentuk polygon, seperti tampak pada Gambar 9. Teknik yang terakhir adalah Teknik Origami Architecture, yaitu teknik lipatan yang membentuk model 3D yang bersifat arsitektural. Secara tampilan visual mirip dengan pop up, tapi origami arsitektur menggunakan satu lembar kertas (Gambar 10).

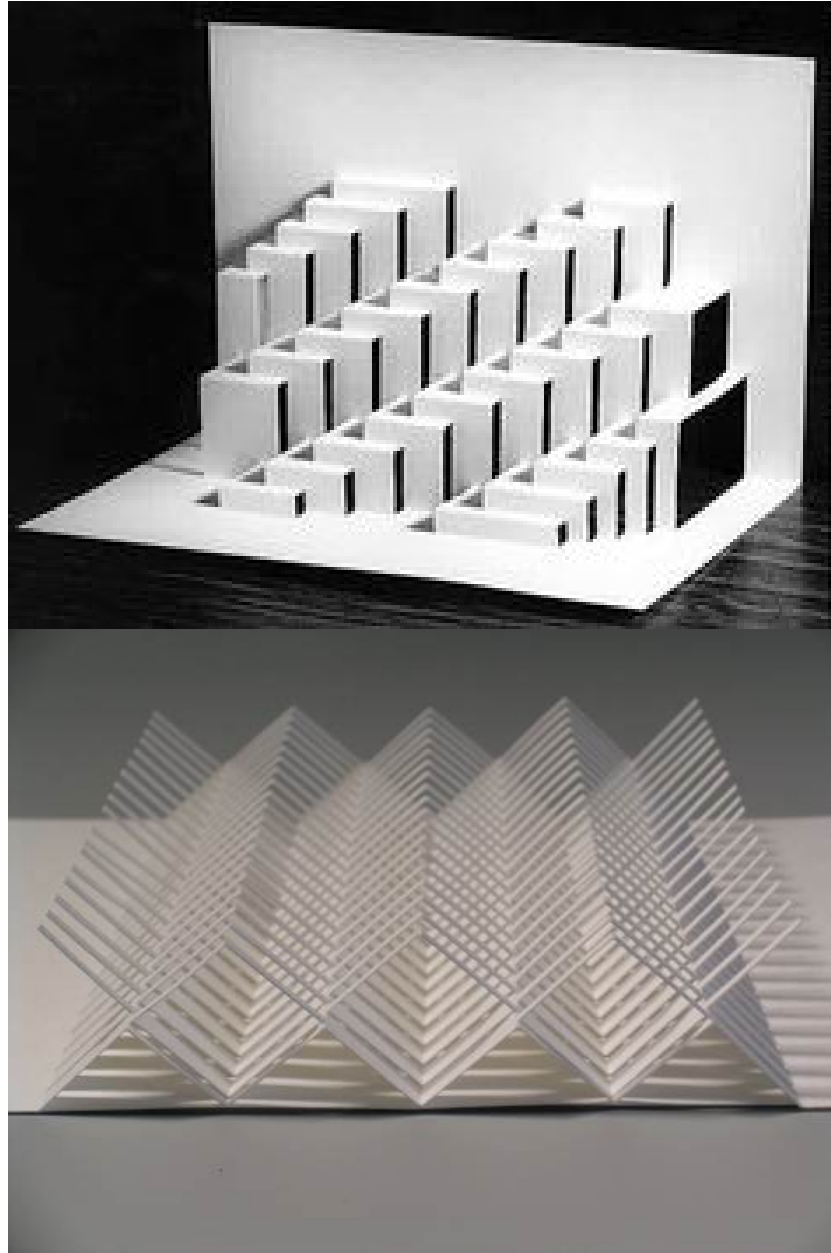

Gambar 10. Contoh Origami Architecture

(Sumber: http://www.visual-arts-cork.com/east-asian-art/origami.htm)

Setidaknya ada 3 jenis produk yang merupakan hasil pengembangan origami, yaitu furnitur, alat bawa, dan lampu. Yang termasuk produk furnitur diantaranya adalah Origami Chair, Papton Chair, dan Flux Chair. Origami Chair merupakan sebuah kursi karya James Dieter, seorang desainer asal Amerika Serikat. Kursi ini berbahan Policarbonat. Dari 1 lembaran dilipat menjadi struktur tiga dimensi dan kuat untuk diduduki orang dewasa (Gambar 11). Sedangkan Pop Chair adalah kursi karya desainer Jerman, Funch dan Funke. Karton kardus dilipat dengan teknik origami (Gambar 12). Material yang dilipat adalah karton kardus. Kursi ini sangat ringan, yaitu $2 \mathrm{~kg}$. Berbeda halnya dengan Flux Chair, sebuah karya desainer Belanda yang hanya terbuat dari 1 lembar polypropelene saja. Dengan teknik origami, kursi ini dapat dilipat menjadi kursi dan dibuka kembali menjadi lembaran sehingga sangat hemat tempat, dan mudah dibawa ke mana - mana (Gambar 13). 


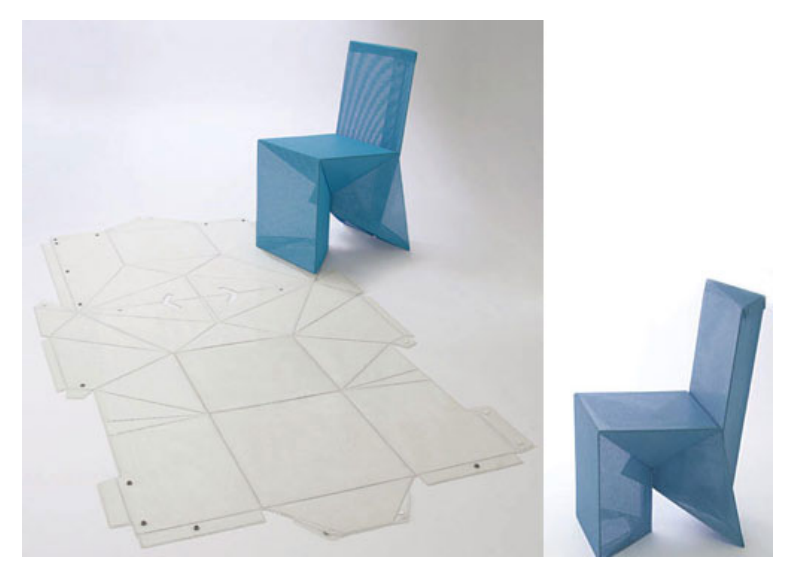

Gambar 11. Origami Chair

(Sumber: https://origamibijou.com/origami-blog/no-973-origami-chair-byjames-dieter)
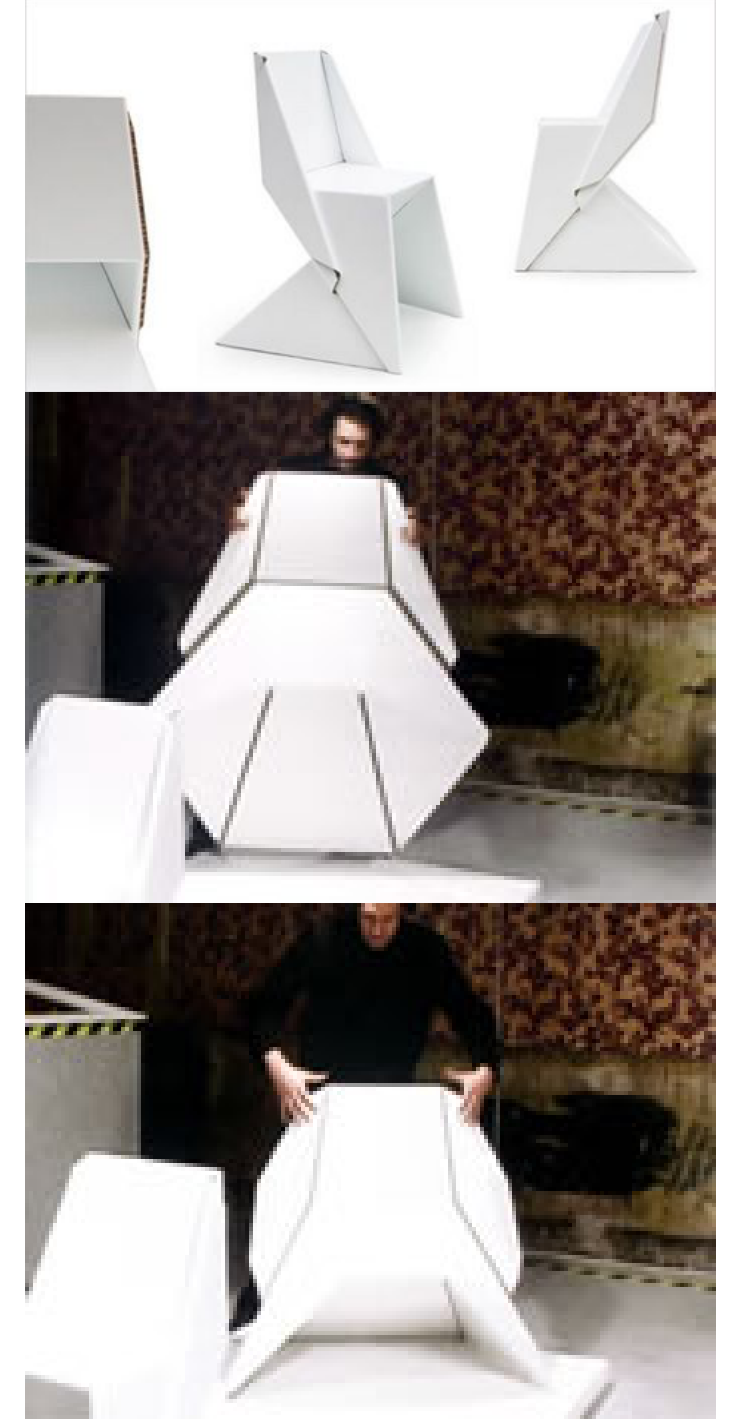

Gambar 12. Papton Chair

(Sumber : http://www.fuchs-funke.de/products/papton/pa01.htm)

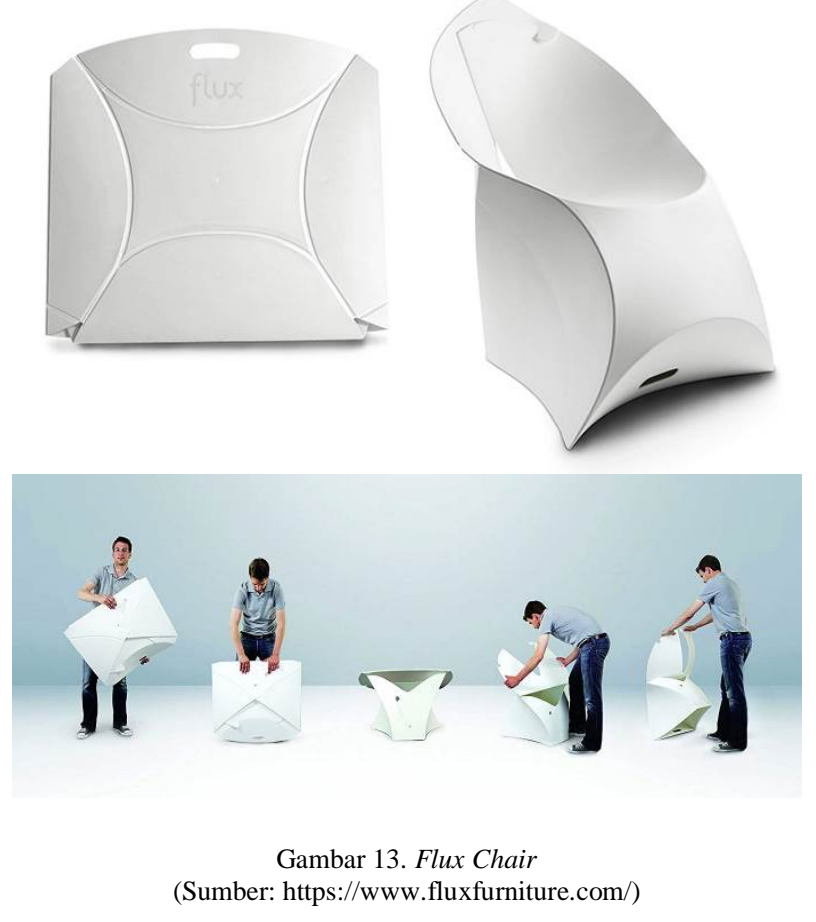

Produk lainnya adalah alat bawa (tas). Tiga contoh aplikasi teknik origami pada alat bawa (tas) adalah Origami bag, Orishiki, dan Transfold Backpack. Yang pertama, Origami Bag, merupakan tas karya James Kunitz. Tas ini berbahan magnetic microfiber, yang membuat kain dapat dilipat dan rekat dengan sendirinya. Jadi dengan satu lembar kain, dapat dilipat menjadi berbagai macam bentuk tas yang dapat disesuaikan dengan aktivitas pengguna (Gambar 14). Produk ini mendapat dana dari Kickstarter, sebuah platform crowdfunding bagi para inventor untuk mendapatkan dana untuk realisasi ide temuan mereka.

Tas yang kedua adalah Orishiki, karya Naomi Kawamoto (Gambar 15). Orishiki diambil dari kata ori dari origami dan shiki dari furoshiki, yaitu seni melipat kain Jepang, yang sering digunakan untuk membuat alat bawa barang, scarf atau sebagai pembungkus hadiah. Sang desainer menggabungkan kedua konsep ini dan mengaplikasikannya dalam desain tas tangan ini. Dari pola lipatan origami yang datar, dapat membungkus barang seperti furoshiki. Sang desainer sudah mengembangkan konsep ini dalam produk lainnya yaitu koper, yang dapat digantung bila koper dibuka, jadi sangat menghemat tempat.

Origami juga diterapkan pada produk lampu. Seperti pada lampu karya Jiangmei Wu, yang dibuat dari $100 \%$ recycled cotton paper (Gambar 16). Lampu ini bila dibentang akan kembali menjadi satu lembar kertas. Selain itu, sebuah produk unik Karya desain sebuah studio di Copenhagen yang disebut "Dono". Dono adalah sebuah pembungkus kado yang 
dapat dipakai ulang, karena dengan lipatan tessellation origami kertas dapat mengikuti bentuk barang yang dibungkus, sehingga kertas dapat dipakai berulang - ulang (Gambar 16).

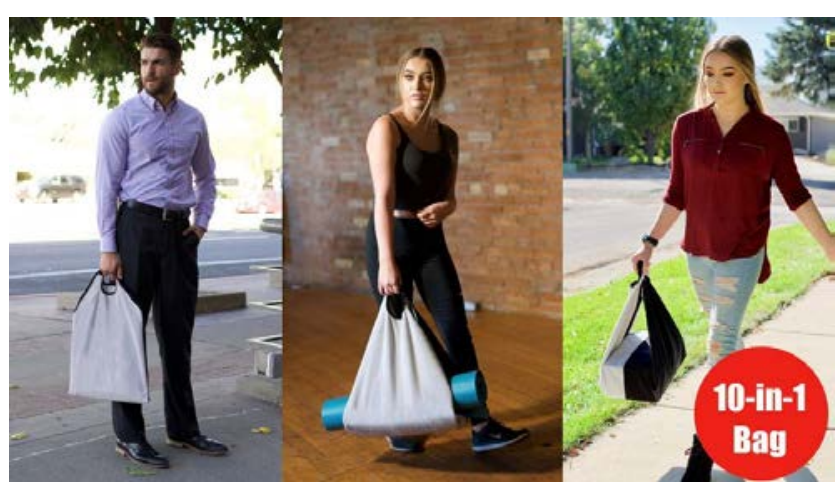

Gambar 14. Tas Origami

(Sumber: https://www.kickstarter.com/projects/1331560229/origami-bagthe-worlds-most-transformable-bag)

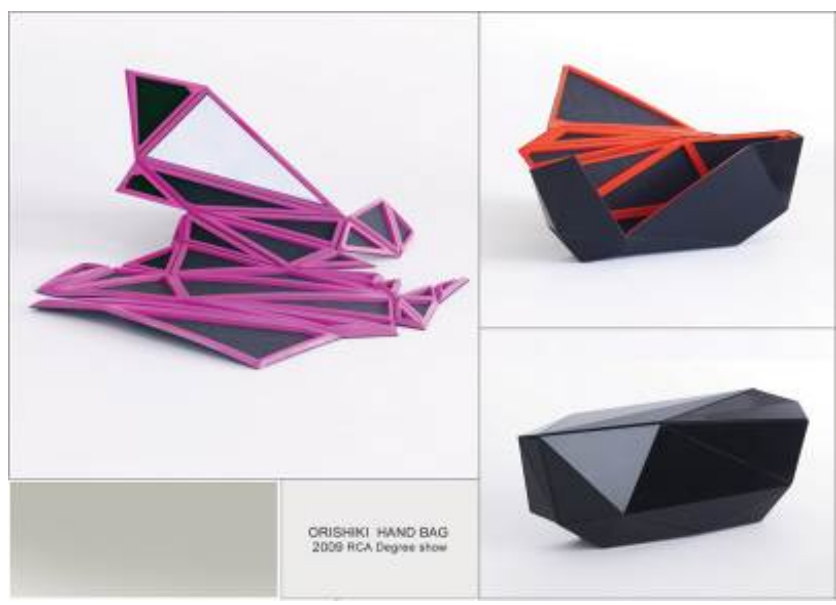

Gambar 15.Tas Orishiki

(Sumber: http://naokikawamoto.com/pg50.html)

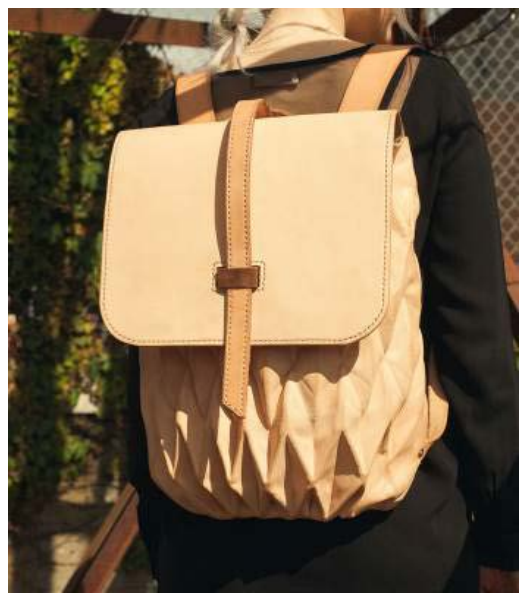

Gambar 16. Tas Transfold

(Sumber: https://design-milk.com/transfold-backpack-bag-expandscontracts/)

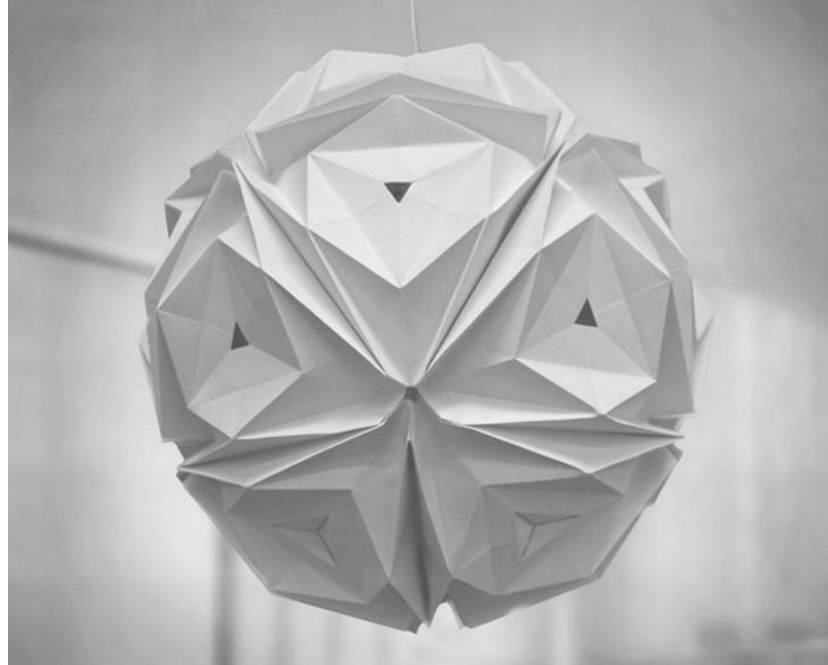

Gambar 17. Lampu Origami

(Sumber: https://jiangmeiwu.com/)

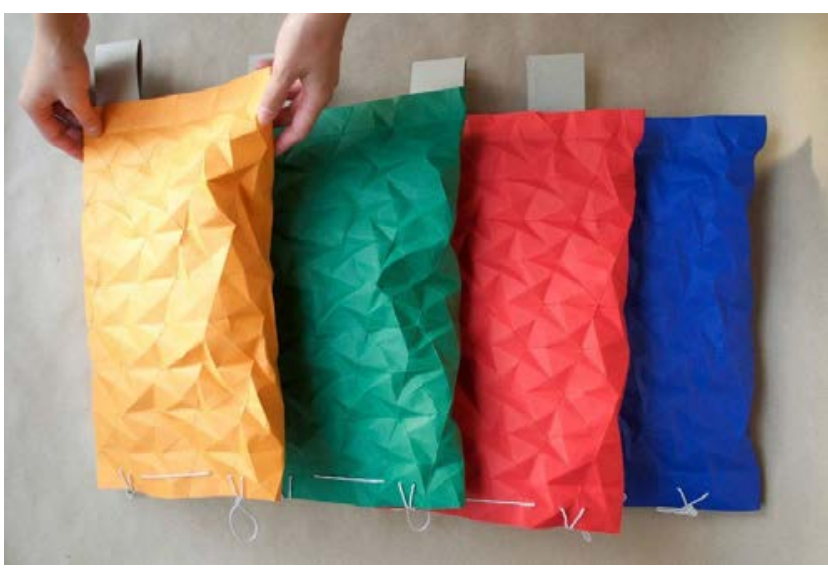

Gambar 18. Kertas Kado Dono

(Sumber: https://inhabitat.com/dono-beautiful-reusable-wrapping-paperinspired-by-origami/)

Setelah melakukan pengamatan beberapa studi kasus origami dalam konteks desain produk, maka dapat diambil beberapa kesimpulan sebagai berikut:

a. Teknik origami dapat dikembangkan pada aneka material non kertas, seperti kain, kulit.

b. Nilai inovasi teknik origami adalah terbuat dari satu lembar material dan tanpa material perekat.

c. Teknik lipatan dapat dikembangkan untuk struktur ataupun sebagai lipatan fleksibel yang dapat mengikuti produk didalamnya.

d. Teknik origami dapat memberikan keunikan hemat tempat penyimpanan, serta mudah dibawa kemana-kemana karena dapat dilipat.

e. Teknik origami membuat material menjadi lebih fleksible.

f. Dengan teknik origami, bentuk produk dapat dirubah. 
g. Dengan teknik origami material dapat menjadi kuat dan $90 \%$ produk dapat dibuat dari satu material.

\section{Desain sebagai Riset}

Riset adalah upaya secara sistematik untuk menginvestigasi ide baru, pemecahan masalah dan eksplorasi potensi output yang dapat menghasilkan kemajuan ilmu pengetahuan (Neuhart et al. 1989). Desain sebagai riset adalah proses menginvestigasi dan mencari solusi dalam proses desain (Chi, 2001; Joost et al. 2016). Sebelum merancang desainer harus meneliti dan menstudi material dan teknologi terbaik untuk merealisasikan produk. Jadi dalam mendesain pasti didahului oleh proses meneliti untuk memahami yang sudah ada serta eksplorasi mencari solusi untuk pengembangan ilmu pengetahuan (Chi, 2001). Dalam konteks penelitian ini, investigasi apakah material MHFPS dapat dibuat dengan prinsip desain modular dengan bentuk dan konfigurasi modular seperti apa yang dapat meminimalisasi limbah sisa potongan.

Penelitian dilakukan dengan metode eksperimen yang diikuti dengan proses perancangan. Penelitian dilakukan secara terstruktur melalui rangkaian eksperimen dengan alur seperti tampak pada Gambar 19.

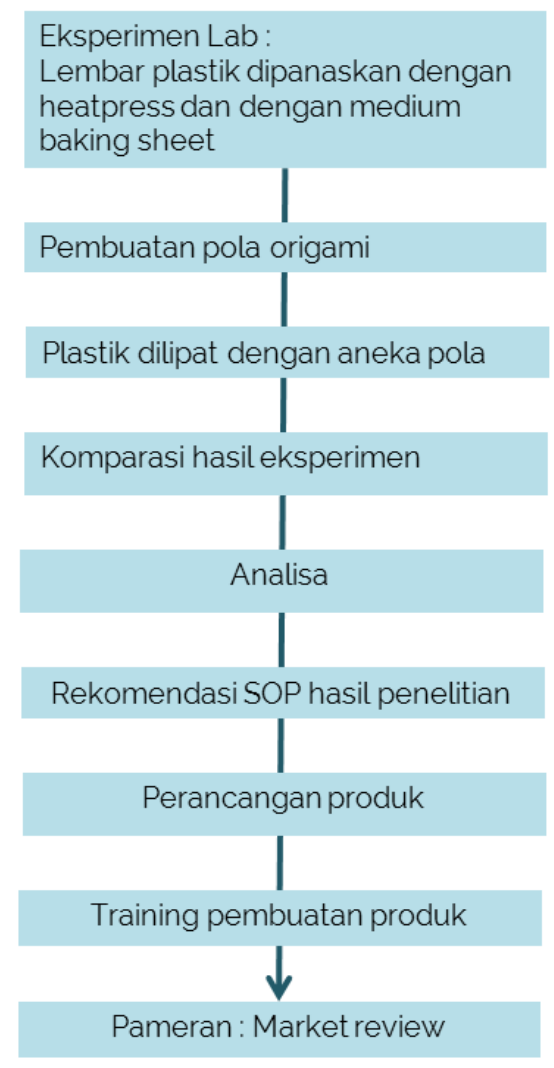

Gambar 19. Diagram alur penelitian

\section{Hasil dan pembahasan}

Pada eksperimen pola, dilakukan analisis eksperimen sebagai berikut: (1) Pola lipatan yang bisa diterapkan pada plastik tidak bisa terlalu rumit, karena plastik lebih tebal tidak setipis kertas; (2) Ketebalan dapat dikombinasikan sehingga bagian - bagian tertentu tidak terlalu tebal. Jadi dalam satu lembar ada yang 4 dan 6 lapis plastik; (3) Agar produk tidak menjadi terlalu tebal, dapat dibuat pola. Sedangkan pada pola origami yang dihasilkan, pola berfungsi sebagai cetakan dan ukuran agar proses melipat konsisten. Pola origami dikembangkan dari pola pola packaging, pola dompet kulit. Pencarian pola yang tepat tidak mudah, diupayakan semua ujung plastik terlipat dan dan dimatikan dengan dipanaskan, dan lipatan tidak boleh terlalu tebal, sehingga dapat diisi dengan barang. Plastik 6 lembar dipanaskan pada suhu $140^{\circ} \mathrm{C}$ bolak balik selama 10 menit.

Produk akhir yang dihasilkan adalah dompet dan stool anak. Produk dompet pada Gambar 20 diperoleh setelah melakukan ujicoba berulang kali. Karena bagian penutup akan ditekuk jadi dua lapisan plastik bertemu dan dipanaskan, maka dibuat dengan lapisan plastik yang lebih sedikit, 4 lembar sedangkan bawahnya 6 lebar, dan disambung dengan dipanaskan. Agar ketika dilipat plastik tidak terlalu tebal dan menyulitkan proses pelipatan. Dengan perbedaan ketebalan, dapat dibuat aneka kombinasi warna dan pola.

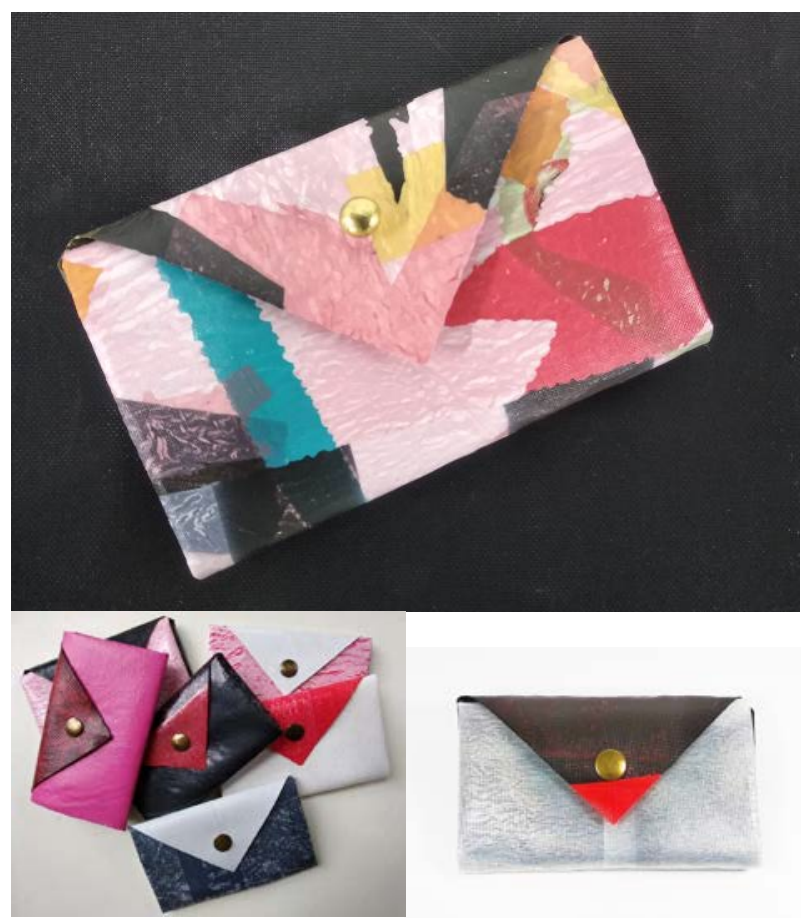

Gambar 20. Dompet Origami 


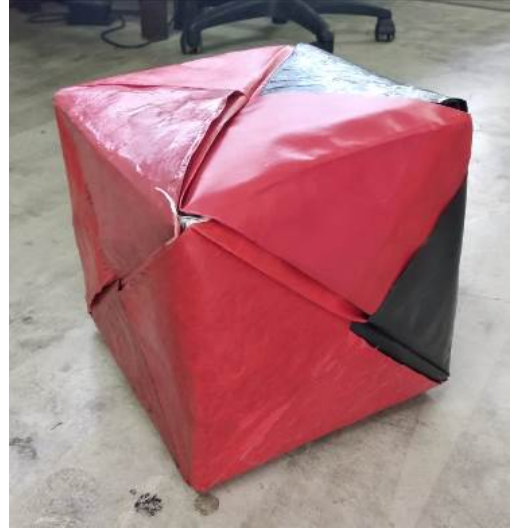

Gambar 21. Stool anak origami

Produk akhir lainnya berupa stool anak. Produk ini merupakan Adaptasi dari modul origami sonobe dimana dibutuhkan 6 buah modul sonobe untuk membuat satu kubus. Hasil akhirnya dapat dilihat pada Gambar 21. Penelitian ini juga menghasilkan luaran PKM berupa kegiatan pelatihan pada 28 siswi SMA IPEKA Tomang, Jakarta dengan tujuan untuk meningkatkan kesadaran generasi muda tentang mendaur ulang sampah plastik. Pola origami dompet yang sudah dihasilkan dari penelitian ini diterapkan dalam pelatihan tersebut.

\section{Kesimpulan}

Berdasarkan penelitian yang telah dilakukan, diperoleh beberapa rekomendasi, sebagai berikut:

a. Untuk dapat dilipat menjadi produk lembaran plastik yang dibutuhkan adalah 4 -6 lembar plastik LDPE yang dipanaskan di suhu $160^{\circ} \mathrm{C}$ selama 10 detik bolak balik.

b. Pola origami yang dapat diterapkan pada material plastik adalah yang bersifat simetri dan tidak bisa terlalu rumit, karena plastik tidak setipis kertas.

c. Ujung dan tepi plastik harus dilipat kedalam dan dipress agar tidak tajam dan terlihat lebih rapih meningkatkan kualitas buatan produk.

d. Kelebihan origami plastik adalah dapat dikombinasikan dua ketebalan plastik yang berbeda. Jadi kita bisa mengatur ketebalan sesuai dengan produk akhirnya.

e. Plastik warna putih ideal menjadi bahan dasar, karena semua warna akan keluar di plastik warna putih kombinasi warna analogous maupun komplementer. Plastik hitam akan menenggelamkan semua warna. Warna merah dapat dikombinasikan dengan warna biru tosca.

f. Bagian - bagian yang mendapat tekanan tarikan yang cukup besar dapat diperkuat dengan menambah lapisan plastik, yang dipanaskan setelah produk dilipat.

g. Untuk menghasilkan produk daur ulang yang dapat disimpan lama, maka perlu diteliti pola plastik yang dapat meningkatkan emosi pengguna.

h. Peserta workshop menyukai proses personalisasi pola dompet dan membentuk pola abstrak, berkreasi dengan warna plastik yang tersedia, jadi setiap dompet unik dan tidak sama satu sama lain.

i. Untuk produk stool sulit untuk dirapihkan, karena lembaran plastik yang besar sulit untuk presisi, jadi hasil lipatan tidak rata. Jadi untuk produk besar memang tidak bisa $100 \%$ terbuat dari plastik perlu material pendukung.

j. Plastik origami harus sekali dilipat dan tidak bisa dibongkar lagi seperti konsep origami yang ada produk lainnya, karena karakter plastic press yang perlu dipanaskan atau dikunci dengan kancing agar bentuknya tidak berubah lagi,

k. Penutup plastik press yang dapat digunakan kancing, magnet ataupun ikatan dari plastik itu sendiri.

Terima kasih disampaikan kepada Dr. Martin L. Katoppo S.T, M.T.selaku Dekan Fakultas Desain Universitas Pelita Harapan dan Dr. Ing. Ihan Martoyo, S.T., M.Sc selaku Ketua LPPM Universitas Pelita Harapan dan berbagai pihak yang telah memberikan bantuan, bimbingan serta kerjasama dalam penyusunan karya ilmiah ini. Artikel ini merupakan publikasi penelitian internal UPH dengan P005/V/SOD/2019 dan terdaftar di LPPM UPH.

\section{Daftar pustaka}

Chi, Lily (2001) Introduction: Design as Research. Journal of Architectural Education, 54(4) 250. DOI: 10.1162/10464880152474565

Collins, Neil. (2008). Origami: The Art of Paper Folding: History, Types, Origamists. Encyclopedia of Asian Art. Retrieved from http://www.visual-arts-cork.com/east-asian-art/origami.htm

Flux Furniture. (2017). The Flux Chair. Retrieved from https://www.fluxfurniture.com/items/chair/

Frenskstudio. (2015) Dono: Beautiful reusable wrapping paper inspired by origami. Retrieved from https://inhabitat.com/dono-beautiful-reusable-wrapping-paperinspired-by-origami/

Fuchs+Funke Industrial Design. (n.d). Papton Chair. Retrieved from http://www.fuchs-funke.de/products/papton/pa01.htm

Gumulya, D., Febriyanti, Meilani, F. (2020). Mendaur ulang sampah kantong plastik low density polyethylene menjadi produk fungsional. Productum: Jurnal Desain Produk (Pengetahuan dan Perancangan Produk). Vol 3 (7). 255-260

Joost, G., Bredies, K., Christensen, M., Conradi, F., \& Unteidig, A. (Eds.). (2016). Design as research: positions, arguments, 
perspectives . Birkhäuser.

Kawamoto, N. (2009). Orishiki Hand Bag. Retrieved from http://naokikawamoto.com/pg50.html

Kunitz, James. (2019). Origami Bag: The World's Most Transformable Bag. Retrieved from https://www.kickstarter.com/projects/1331560229/origamibag-the-worlds-most-transformable-bag

Neuhart, J., Neuhart, M., and Eames, R. (1989) Eames Design: The work of the office of Charles and Ray Eames, New York: Harry N. Abrams.
Sung, Kyungeun. (2015). A Review on Upcycling: Current Body of Literature, Knowledge Gaps and a Way Forward. Conference: International Conference on Environmental, Cultural, Economic and Social Sustainability.Venice. Vol 17 (4). $28-40$

Williamson, Caroline. (2014). Transfold Backpack: A Bag that Expands and Contracts. Retrieved from https://designmilk.com/transfold-backpack-bag-expands-contracts/

Wu, Jiangmei (2020). Folded Light Art. Retrieved from https://jiangmeiwu.com/folded-light-art/ 